\title{
Dynamic Behavior and Energy Evolution Characteristic of Deep Roadway Sandstone Containing Weakly Filled Joint at Various Angles
}

\author{
Qinyong Ma $\mathbb{D}^{\mathbb{D}},{ }^{1,2,3}$ Qingqing $S u \mathbb{D}^{1,2,3}$ and Pu Yuan $\mathbb{i}^{1,2,3}$ \\ ${ }^{1}$ State Key Laboratory of Mining Response and Disaster Prevention and Control in Deep Coal Mine, \\ Anhui University of Science and Technology, Huainan, Anhui 232001, China \\ ${ }^{2}$ Engineering Research Center of Underground Mine Construction, Ministry of Education of China, \\ Anhui University of Science and Technology, Huainan, Anhui 232001, China \\ ${ }^{3}$ School of Civil Engineering and Architecture, Anhui University of Science and Technology, Huainan, Anhui 232001, China \\ Correspondence should be addressed to Qingqing Su; qqsuhn@126.com
}

Received 20 May 2020; Revised 10 July 2020; Accepted 31 July 2020; Published 24 August 2020

Academic Editor: Fengqiang Gong

Copyright (C) 2020 Qinyong Ma et al. This is an open access article distributed under the Creative Commons Attribution License, which permits unrestricted use, distribution, and reproduction in any medium, provided the original work is properly cited.

\begin{abstract}
Dynamic impact tests were carried out by implying split-Hopkinson pressure bar (SHPB) apparatus under three-dimensional stress state to investigate the influences of weakly filled joint at seven kinds of angles on dynamic behavior and energy evolution characteristic of deep roadway sandstone ( $985 \mathrm{~m}$ below the surface). The results indicated that rebound strain phenomenon was obvious and the growth rate of stress was in two kinds of phased variations. Dynamic peak strain was inversely proportional to joint angle under three different strain rates. Dynamic compressive strength, elastic deformation modulus, and plastic deformation modulus were in similar variable tendencies with incremental joint angles, showing firstly decrease to minimum value at joint angle of $45^{\circ}$ and then increase to maximum value at joint angle of $90^{\circ}$. Moreover, the sensitivity of plastic deformation modulus to joint angle was obviously inferior to that of elastic deformation modulus when joint angle increased from $0^{\circ}$ to $45^{\circ}$. Furthermore, both elastic deformation modulus and plastic deformation modulus were independent of strain rate, which was contrary to dynamic compressive strength and dynamic peak strain. Additionally, absorption energy release rate was introduced and defined to describe energy release and conversion characteristics of joint specimens. The changed trend of energy reflection coefficient was completely opposite to that of energy transmission coefficient and absorbed energy release rate. Absorbed energy density was linearly decreased with incremental joint angle and was increased with the increase of strain rate.
\end{abstract}

\section{Introduction}

Deep mining was the inevitable trend of future development. Deep rock mass, which was affected by geological tectonic movement and human activity, contained various defects, such as joints, flaws, and fractures. As a kind of filled fracture, weakly filled joint universally existed in natural rock masses, resulting in degraded mechanical properties of deep rock masses and reduced stability of underground structures. And joint angle was a critical parameter in joint geometry, with notable influences on energy evolution characteristic and rock-breaking efficiency. Moreover, dynamic disturbance and stress state were significant factors affecting the mechanical properties of deep rock masses $[1-4]$. Hence, it was a tremendous necessity to investigate the effects of weakly filled joint at various angles on dynamic behavior and energy evolution characteristic of deep sandstone under three-dimensional stress state to provide scientifically guidance for practical projects.

Numerous efforts had been devoted to investigating mechanical behaviors of intact rock specimens under static or dynamic loading with various stress states [5-10]. And there were relatively few studies that investigated the effects of preexisting defects on deformation features and crack coalescence categories of rock mass. Gong et al.'s [11] experimental simulation investigated the rockburst characteristics in deep 
circular tunnels by utilizing a true triaxial system under four different initial stresses and revealed the mechanism of rockburst induced by spalling damage. The diameter of hole and lateral stress had significant influences on rockburst. Wu et al. [12] studied the dilatancy, acoustic emission, and failure characteristics of rock specimens with two preexisting flaws under uniaxial and triaxial loading states. Moreover, the crack evolution and failure features were closely related to loading rate and confining pressure. Bai et al. [13] carried out triaxial tests in laboratory to solve ice-rock coupled problem of red sandstone with two preexisting ice-filled fissures. The relationship between shear strength $\left(\sigma_{1}-\sigma_{3}\right)$ and confining stress was nonlinear, which was opposite to peak strength, elastic modulus, and shear strength parameters. Wang et al. [14] studied the strength and the failure mode of a heterogeneous rock mass by combining numerical simulation and acoustic emission technology under conventional triaxial compression. Confining pressure could inhibit the development of tensile cracks, but facilitate the coalescence of shear cracks. Both discretized virtual internal bond model and element partition method were utilized by Yang et al. [15] to simulate and get insight into failure sequences of rock with single flaw or multiple flaws under unloading conditions. The fracturing processes and failure modes were significantly influenced by configuration of randomized flaws, whereas the amount of flaws could slightly affect acoustic emission counts. Li et al. [16] combined experimental analysis with theoretical derivation to describe stress distribution around the circular and elliptical hole contained in specimens under axial compression and found that digital image correlation technology could well reflect crack coalescence processes at different stress stages. Liu et al. [17] proposed a damage constitutive model to analyze deformation and strength properties of rock with intermittent joints under cyclic axial compression. Yang et al. [18] considered that U-shaped variation in peak strength and elastic modulus of nonpersistent jointed rock specimens was obvious with incremental joint inclination, and shear slipping cracks easily occurred at the sidewalls of circular hole. Si and Gong [19] considered that the weakening effect was positively related to unloading rate and confining pressure. However, a higher unloading rate would lead to a weaker rockburst, and a more severe rockburst resulted from a higher confining pressure. The failure mode transformation, i.e., shear failure in triaxial compression tests transformed to tension failure in triaxial unloading compression tests, was the central reason for the weakening of strength.

However, aside from static loadings, dynamic loadings were universally distributed in deep underground engineering. And various defects in rock masses performed significant effects on mechanical behaviors and energy evolution characteristics. Han et al. [20] found that flaw inclination angle and ligament angle remarkably affected dynamic compressive strength and dynamic deformation properties, respectively. Liu et al. [21] comparatively analyzed energy consumption properties of vertical bedded and parallel bedded coal-rock and observed that more energy would be needed by vertical bedded coal-rock for the same fractal dimension. Yuan et al. [22] investigated the effect of joint angle on zonal disintegration under coupled high in situ axial stress and blasting load and found that the number of cracks after blasting and released strain energy had similar variable tendency. Li et al. [23] carried out a series of dynamic tests to study the influences of joint roughness coefficient on wave energy attenuation and introduced a new method based on stress wave energy to calculate seismic quality factor, which was simpler than traditional approach dependent on stress-strain curves. Wang et al. [24] theoretically analyzed the effects of various parameters of stress wave and joint gap width on energy transmission coefficient. There was an optimal incident angle of stress wave to maximize the transmission coefficient and a critical width of joint gap existed for effective propagation of stress wave. $\mathrm{Li}$ et al. [25] found that, under coupled dynamic and static loads, the influences of axial pressure and incident energy on the mechanical parameters of flawed granite were significant. With the increase of axial pressure, the energy absorption rate of granite with single flaw increased first and then decreased, which was inversely proportional to impact pressure. Chen et al. [26] found that the interference of detachment wave was adverse to achieve stress equilibrium of specimen and could be avoided by adopting two strain gauges mounted on the incident bar at different locations to separate the detachment wave and reflected wave in triaxial SHPB tests. Additionally, in terms of rock masses with filled joint, the propagation mechanisms of stress wave were the central issues of scholars. Zou et al. [27] derived the solutions in time domain for plane wave propagation across filled joint based on Maxwell and Kelvin models and considered that the stiffness and the viscosity of joints, incident angle, and duration of incident waves had notable effects on propagation and attenuation of stress wave. Cai et al. [28] adopted theoretical analysis with the displacement discontinuity model to describe the effects of stiffness, spacing, and number of parallel fractures on wave attenuation and found that the ratio of fracture spacing to wavelength was a determining factor for the dependence of transmission coefficient on fracture spacing and number. Zhu et al. [29] found that the displacement and stress discontinuity model could well characterize the seismic response of the filled joint and the incident angle, joint stiffness. The nondimensional joint viscosity and the impedance ratio of the filled joint had significant effects on reflection coefficient and transmission coefficient. Li et al. [30] demonstrated theoretically that similar variable tendencies of transmitted wave were obtained for parallel joints and single joint under different incident angles and frequencies, and the number of joints was inversely proportional to transmission coefficient.

It could be safely accepted that weakly filled joint at various angles had notable influences on dynamic behavior and energy evolution mechanism of rock masses. Many engineering accidents were caused by neglecting the dramatic change of lithology around the weakly filled joints. However, insufficient researches had been conducted on the dynamic behavior and energy evolution mechanism of rock masses possessing weakly filled joint with various angles. In the present study, a series of dynamic compressive tests were carried out to investigate the influences of weakly filled joint at seven kinds of angles on dynamic properties and energy 
evolution characteristics of deep roadway sandstone (985 m below the surface) under three-dimensional stress state coupled with three different strain rates. The variations in dynamic stress-strain curves, dynamic compressive strength, dynamic peak strain, elastic deformation modulus, plastic deformation modulus, typical energy-time curves, absorbed energy release rate, absorbed energy density, energy transmission coefficient, and energy reflection coefficient were analyzed in detail.

\section{Testing Specimens and Experimental Methods}

2.1. Preparation of Testing Specimens. Specimens containing weakly filled joint were made of sandstone and gypsum, divided into seven types according to joint angle $\alpha$, i.e., $0^{\circ}$, $15^{\circ}, 30^{\circ}, 45^{\circ}, 60^{\circ}, 75^{\circ}$, and $90^{\circ}$, as shown in Figure $1(\mathrm{a})$ and Figure 1(b). The joint angle $\alpha$ was defined as the acute angle formed by joint and cross section of specimen. And the sandstone was selected from a roadway $985 \mathrm{~m}$ below the surface of a coal mine located in Huainan, Anhui province of China, which was composed of quartz $(85 \%)$, microcline $(6.8 \%)$, muscovite $(4.6 \%)$, albite $(2.2 \%)$, and small amount of other minerals $(1.4 \%)$ as determined by XRD analyses, as displayed in Figure 1(c). Firstly, intact cylinder core without obvious defects was drilled from a sandstone block; then the cylinder specimens were cut into two parts on the basis of designed joint angle by rock cutting machine. Secondly, prefabricated joints with a thickness of $4 \pm 1 \mathrm{~mm}$ (same thickness as cutter blade) were made of gypsum (the weight ratio of gypsum to water was 2:1). The joint and paired sandstone pieces were cemented by gypsum. Finally, both ends of specimens were grinded and polished to control unevenness and nonperpendicularity less than $0.2 \mathrm{~mm}$. The qualified jointed specimens were with size of $50 \mathrm{~mm}$ in diameter and $50 \mathrm{~mm}$ in height following the method suggested by the International Society for Rock Mechanics (ISRM) [31].

2.2. Testing Equipment. The dynamic tests were conducted by employing a modified SHPB apparatus coupled with confining pressure system and data processing system. The modified SHPB equipment was consisted of an axial compressive system, elastic bars (i.e., an incident bar, a transmitted bar, and an absorbing bar), a cone-shaped striker, a launch device, and a laser speedometer. The elastic bars were all made of high-strength alloy steel with Young's modulus $E$ of $210 \mathrm{GPa}$, density of $7900 \mathrm{~kg} / \mathrm{m}^{3}$, and $\mathrm{P}$-wave propagation velocity of $5100 \mathrm{~m} / \mathrm{s}$. Data acquisition and processing system was composed of bridge boxes, an oscilloscope, a dynamic resistance strain gauge, a chronograph, a computer, and strain gauges mounted on elastic bars. The experimental procedure could be described as follows: (1) The confining pressure system was carefully debugged, and an appropriate amount of Vaseline was daubed to eliminate as much frictional force as possible between interior surface of confining pressure chamber and elastic bars. (2) Jointed specimen was put into confining pressure chamber of confining pressure system and sandwiched the jointed specimen between incident bar and transmitted bar. (3) The confining pressure was applying until the jointed specimen was loaded with $1 \mathrm{MPa}$, and then the axial precompressive stress was also loaded with $1 \mathrm{MPa}$, which could effectively avoid the failure of specimen with weakly filled joint prior to dynamic loading. We had determined that the active confining pressure and axial precompressive stress were both $1 \mathrm{MPa}$ after many tests. The reasons behind this determination were stated as follows. Weak cementation action between rock matrix and joint plane made the jointed specimen separated locally along cementation planes under lower axial precompressive stress. Although the jointed specimen had not reach static compressive strength at this moment, considerable influence of prior local separation on stress wave propagation had formed under dynamic loading. (4) Gas pressure was adjusted to generate desired strain rate, and the pressure switch was opened to accelerate the coneshaped striker hitting the incident bar with the strain rate $\dot{\varepsilon}$ around of $30 \mathrm{~s}^{-1}, 85 \mathrm{~s}^{-1}$, and $105 \mathrm{~s}^{-1}$, respectively. Simultaneously the elastic stress pulses were captured and displayed by oscilloscope, dynamic resistance strain gauge, and the strain gauges mounted on the incident bar and transmitted bar. (5) Finally, fragments of specimen were collected after test, and the confining pressure chamber was cleared.

2.3. Stress Equilibrium. Stress equilibrium prior to failure, as an essential assumption to ensure valid test dates, was significantly important to jointed specimens. A cone-shaped striker, which was conducive to generate a slowly rising half sine wave, was utilized to provide sufficient loading time for stress equilibrium of jointed specimens. In terms of jointed specimen, typical impulse waveform and dynamic stress equilibrium were displayed by Figure 2 . The half sine wave with an approximate duration of $400 \mu$ s was smooth, which implied that the dispersion effect of stress wave could be neglected. And the sum of incident stress and reflected stress was closely inconsistent with transmitted stress, especially for the section of stress equilibrium curves before reaching peak value. Hence, jointed specimens could well satisfy the requirement of stress equilibrium under the condition of static-dynamic coupling loading in the present SHPB tests. Based on one-dimensional stress wave propagation theory, the axial stress $\sigma(t)$, strain $\varepsilon(t)$, and strain rate $\dot{\varepsilon}(t)$ of jointed specimens could be calculated through "three-wave analysis" [32].

\section{Dynamic Mechanical Behavior}

3.1. Stress-Strain Relationship. Typical stress-strain curves for jointed specimens were presented in Figure 3. Based on the occurrence of filled joints [33], specimens with a joint angle of $0^{\circ}, 15^{\circ}, 30^{\circ}$, and $45^{\circ}$ were entitled as category I jointed specimens, and specimens containing a joint angle of $60^{\circ}$, $75^{\circ}$, and $90^{\circ}$ were called after category II jointed specimens. And representative stress-strain curves of category I jointed specimens and category II jointed specimens were shown in Figure 3(a). In general, the stress-strain curves of jointed 


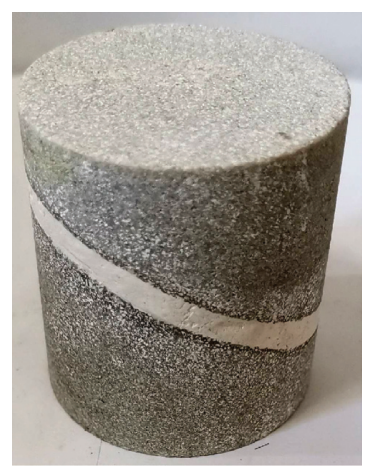

(a)

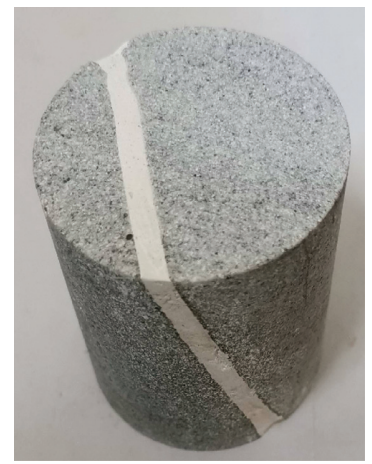

(b)

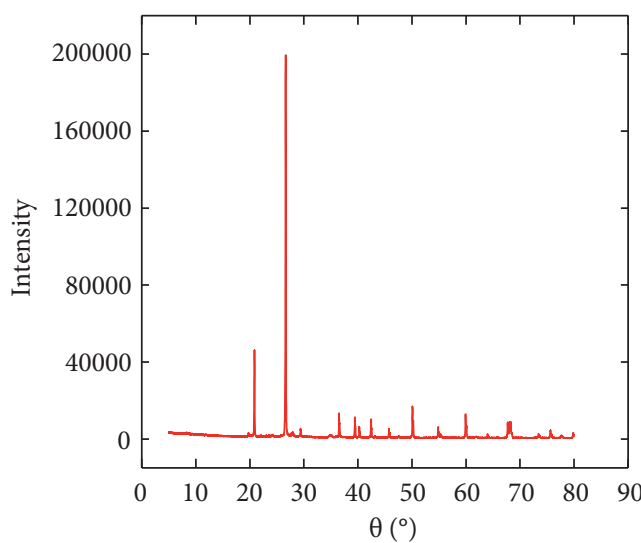

(c)

Figure 1: Physical pictures of jointed specimens and XRD diffraction pattern of sandstone. (a) Specimen with a joint angle of $30^{\circ}$. (b) Specimen with a joint angle of $60^{\circ}$. (c) XRD diffraction pattern of sandstone.

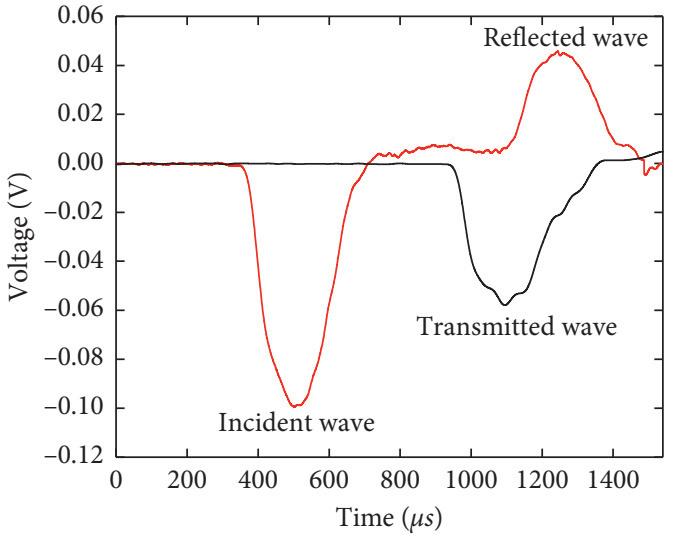

(a)

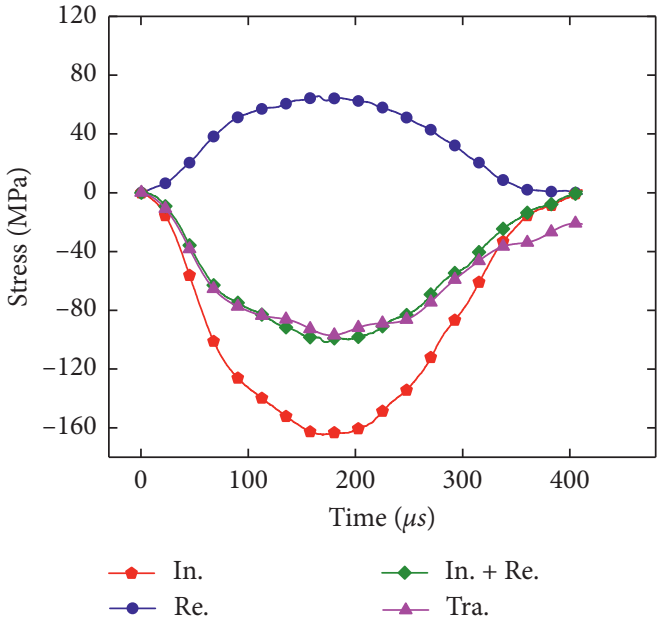

(b)

Figure 2: (a) Typical wave form of electrical signal and (b) dynamic stress equilibrium of jointed specimen.

specimens could be sequentially divided into three stages (i.e., elastic stage, plastic stage, and unloading stage) according to the evolutionary characteristics of stress-strain curve. Moreover, the notable differences of stress-strain curves between the two categories of jointed specimens were performed in plastic stage and unloading stage. The plastic stage of category I jointed specimens could be further subdivided as the first plastic section $\mathrm{AB}$ and the second plastic section BC. Similar as the plastic stage PQ of category II jointed specimens, the first plastic section $A B$ also performed remarkably rising trend with a considerable slope, whereas the second plastic section $\mathrm{BC}$ was keeping slowly ascending tendency. It was indicated that the deformation capacity of category I jointed specimens was vastly superior to that of category II jointed specimens. Furthermore, the stresses of the first unloading section QR for category II jointed specimens would fall dramatically, which generally showed the growth rate of "fast-fast" two sections characteristics, while slight decline of stresses for category I jointed specimens firstly occurred after reaching maximum stress and then plunged linearly, with the growth rate of "fastslow-slow-fast" four sections characteristics. From Figures $3(\mathrm{~b})-3(\mathrm{~d})$, the failure mode of category I jointed specimens was obviously plastic failure feature. Conversely, there had been dramatically growing tendency of the brittle failure feature for category II jointed specimens as joint angle increased from $60^{\circ}$ to $90^{\circ}$. The plastic feature of category I jointed specimens and the brittle behavior of category II jointed specimens were both notable under higher strain rate.

Moreover, the rebound strain phenomenon was observed in both category I jointed specimens and category II jointed specimens. The reasons behind the phenomenon might be as follows. From Figure 4, the ultimate failure modes of jointed specimens were the separation between joint and sandstone matrix. The crack coalescence and propagation in jointed specimens were restrained under three-dimensional stress state, which was conducive to the 

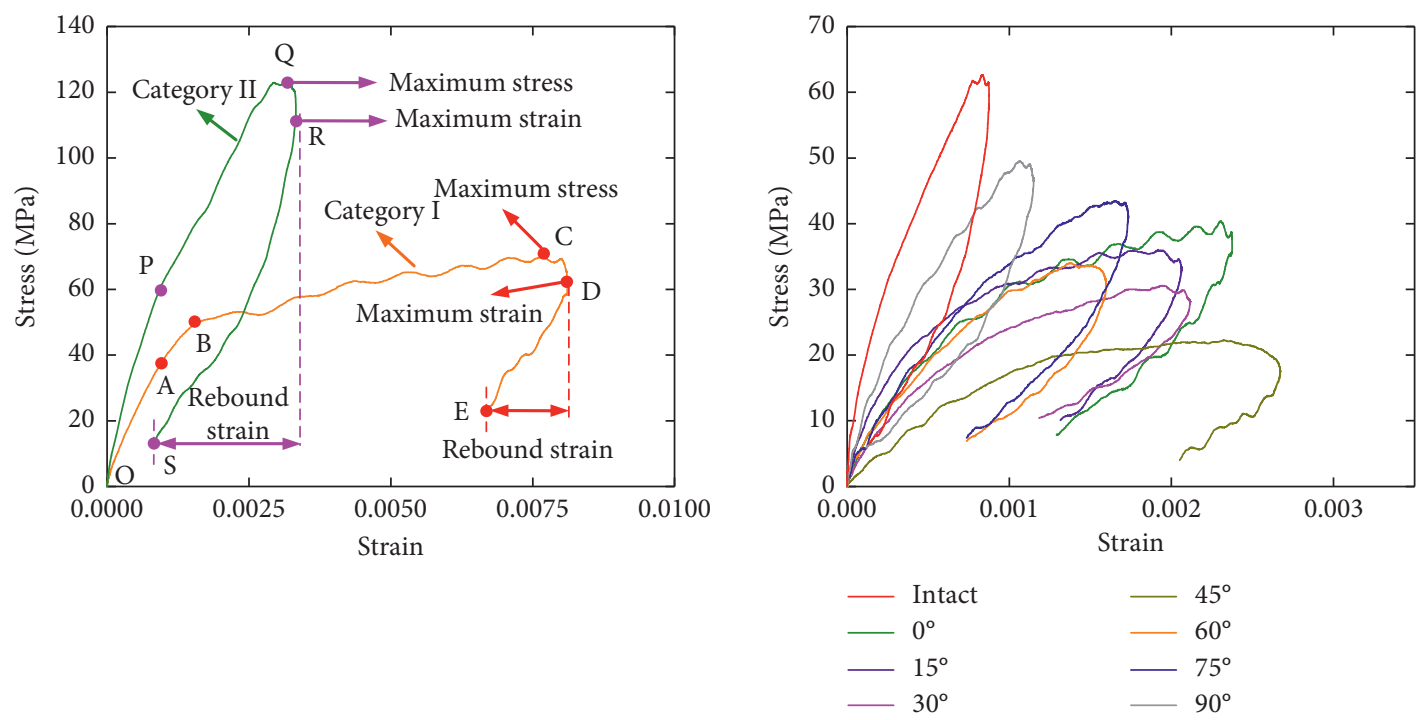

(a)

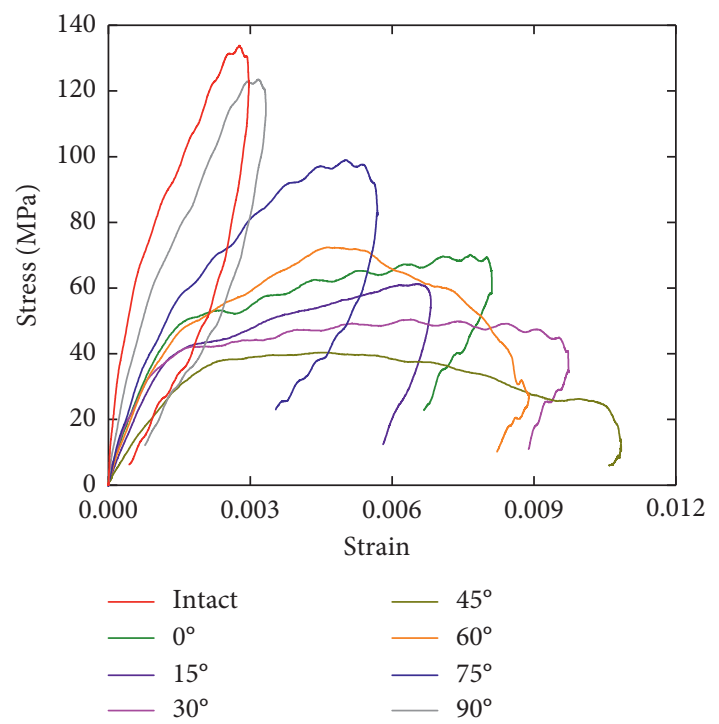

(c)

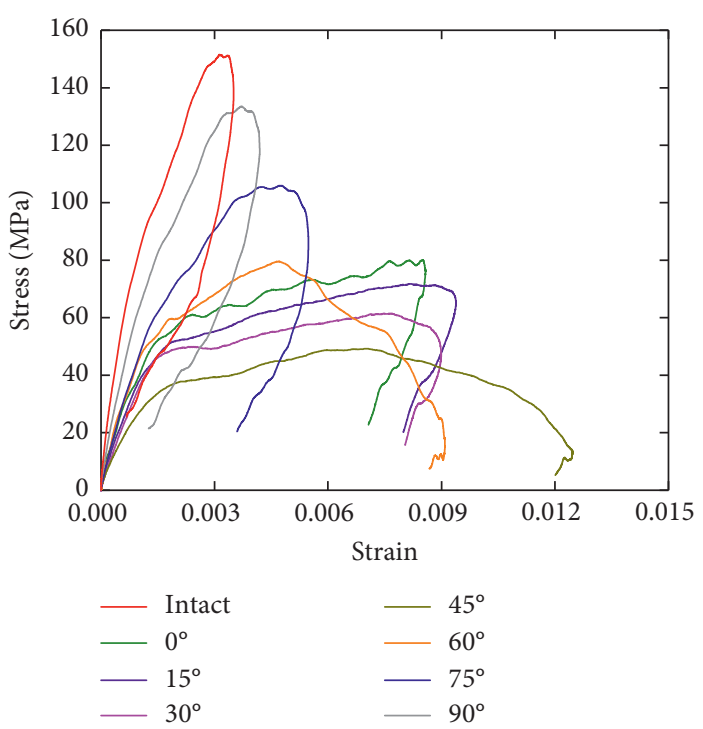

(d)

FIGURE 3: Stress-strain curves of intact specimens and jointed specimens. (a) Subsection methods of stress-strain curve; (b) the average strain rate $\dot{\varepsilon}=30 \mathrm{~s}^{-1}$; (c) the average strain rate $\dot{\varepsilon}=85 \mathrm{~s}^{-1}$; and (d) the average strain rate $\dot{\varepsilon}=105 \mathrm{~s}^{-1}$.

accumulation of elastic deformation energy in jointed specimens. The release of elastic deformation energy gathered in sandstone matrix was the primary cause of the rebound strain phenomenon [34].

\subsection{Effects of Joint Angle and Strain Rate on Dynamic Strength.} The relationship of dynamic compressive strength of intact specimens and jointed specimens against joint angle and strain rate was plotted in Figure 5. In general, the dynamic compressive strengths of jointed specimen were lower than those of intact specimens and were proportional to strain rate. For a constant strain rate, the maximum value of dynamic compressive strength has occurred at joint angle of $90^{\circ}$, which was slightly smaller than the dynamic compressive strength of intact specimen, while the joint angle of $45^{\circ}$ minimized the dynamic compressive strength. When the strain rate was at around $105 \mathrm{~s}^{-1}$, the average dynamic strength of intact sandstone specimen and jointed specimen in the descending order was $151.05 \mathrm{MPa}, 132.18 \mathrm{MPa}$, 107.24 MPa, $\quad$ 81.02 $\mathrm{MPa}, \quad$ 80.39 $\mathrm{MPa}, \quad 71.16 \mathrm{MPa}$, $62.72 \mathrm{MPa}$, and $49.46 \mathrm{MPa}$, with multiple relationships from 1.14 times to 3.05 times. It was implied that joint angle had a strong effect on dynamic strength of sandstone. Moreover, dynamic compressive strength of jointed specimens was linearly decreased as the joint angle increased from $0^{\circ}$ to $45^{\circ}$ and then significantly increased to maximum value with the mounting joint angle from $60^{\circ}$ to $90^{\circ}$, which was changed in $\mathrm{V}$-shape. And the higher the strain rate was, the more obvious the $\mathrm{V}$-shaped change was. 


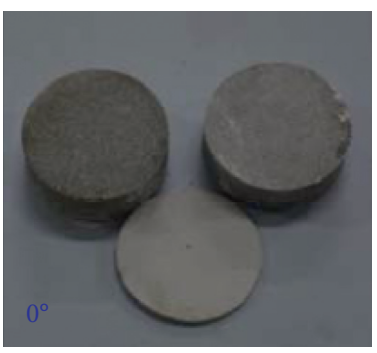

(a)

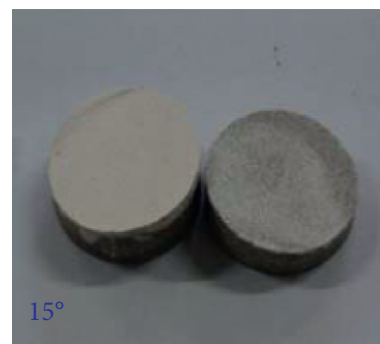

(b)

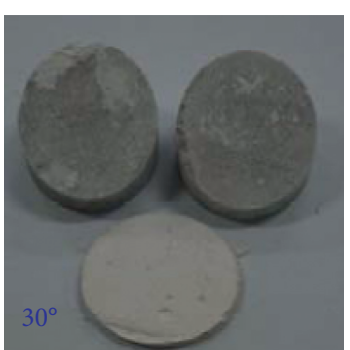

(c)

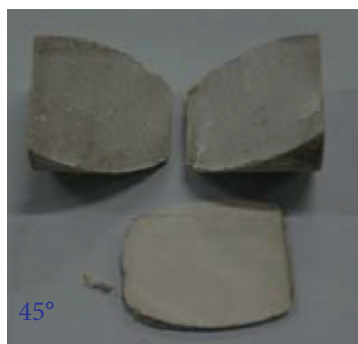

(d)

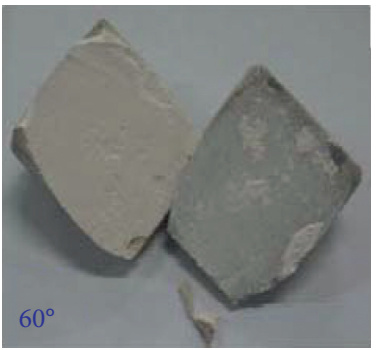

(e)

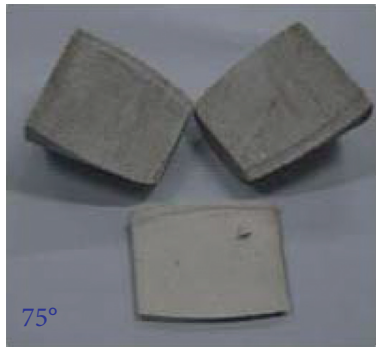

(f)

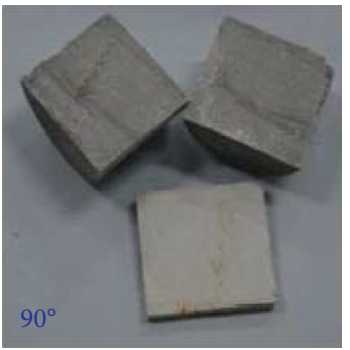

(g)

Figure 4: The failure modes of specimens with various joint angles under the strain rate of $85 \mathrm{~s}^{-1}$.

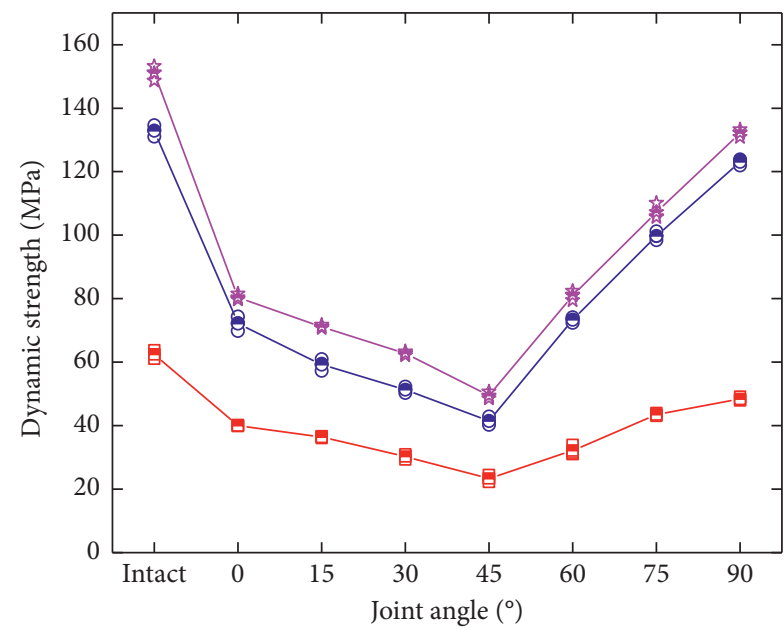

$\begin{array}{ll}\square \text { Test values, } \dot{\varepsilon}=30 s^{-1} & -\Xi-\text { Average values, } \dot{\varepsilon}=30 s^{-1} \\ \text { ○ Test values, } \dot{\varepsilon}=85 s^{-1} & -\diamond-\text { Average values, } \dot{\varepsilon}=85 s^{-1} \\ \text { « Test values, } \dot{\varepsilon}=105 s^{-1} & -\star-\text { Average values, } \dot{\varepsilon}=105 s^{-1}\end{array}$

FIGURE 5: Relationship between dynamic compressive strength and joint angle under three different strain rates.

\subsection{Effects of Joint Angle and Strain Rate on Dynamic Peak} Strain. The tendencies of dynamic peak strain of specimens under three kinds of strain rates were shown in Figure 6. Dynamic peak strain under an average strain rate of $85 \mathrm{~s}^{-1}$ or $105 \mathrm{~s}^{-1}$ was gradual decline as joint angle increased from $0^{\circ}$ to $90^{\circ}$, which was obviously different to that under one-dimensional stress state [35]. However, the dynamic peak strain performed slight fluctuation under the average strain rate of $30 \mathrm{~s}^{-1}$, which might be resulted from that the lower incident energy generated marginal damage and deformation to jointed specimen under three-dimensional stress states. Hence, the deformation characteristics of joint

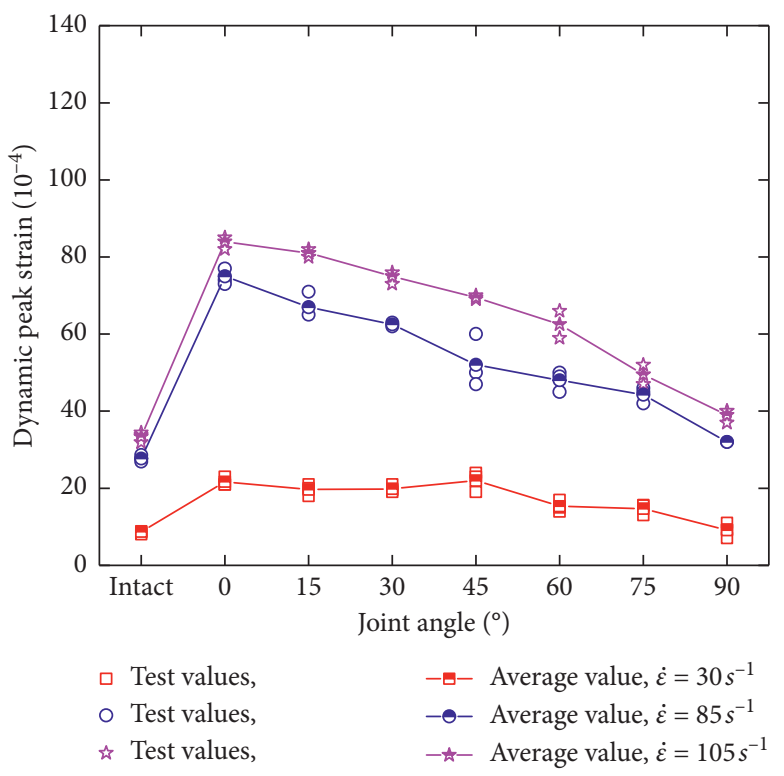

FIgURE 6: Relationship between dynamic peak strain and joint angle under three different strain rates.

specimens were not entirely revealed, which resulted in an unapparent variation tendency of dynamic peak strain. Moreover, the dynamic peak strain of intact specimens was the minimum and was slightly lower than that of specimen with a joint angle of $90^{\circ}$, while the maximum value of dynamic peak strain for jointed specimens has occurred at joint angle of $0^{\circ}$. These phenomena could be explained as follows. Weakly filled joint with a certain thickness was compressive large deformation material compared with sandstone matrix and brought about a great influence on dynamic peak strain, especially for specimens with a smaller joint angle. There was a large part of dynamic peak strain that came from the 
compression deformation of weakly filled joint. And the compression deformation of weakly filled joints increased with the decrease of joint angle. Obviously, the compression deformation of joint reached the maximum value at joint angle $\alpha=0^{\circ}$, whereas the minimum value appeared at joint angle of $90^{\circ}$.

3.4. Effects of Joint Angle and Strain Rate on Deformation Modulus. Elastic deformation modulus $E_{1}$ and plastic deformation modulus $E_{2}$ were defined to describe elastic and plastic deformation behaviors of jointed specimens according to previous research of sandstone materials, as shown in Figure 7. Elastic deformation modulus $E_{1}$ was equal to the slope of the straight line between the point corresponding to $50 \%$ peak stress and coordinate origin. And plastic deformation modulus $E_{2}$ was equal to the slope of the straight line between the point corresponding to peak stress and the point corresponding to $50 \%$ peak stress. The dependence of elastic deformation modulus $E_{1}$ and plastic deformation modulus $E_{2}$ on joint angle was presented in Figure 8. Conspicuous change of $E_{1}$ for jointed specimens possessing weakly filled joint at various angles was not observed as the strain rate increased from $30 \mathrm{~s}^{-1}$ to $105 \mathrm{~s}^{-1}$, but performed regularly prominent fluctuation with variable joint angle. Notably, $E_{2}$ with the strain rate of $30 \mathrm{~s}^{-1}$ was minor greater than that when the strain rate was at around $85 \mathrm{~s}^{-1}$ or $105 \mathrm{~s}^{-1}$. The reasons behind this phenomenon were as follows. The ability of three-dimensional stress state to restrain plastic deformation was more considerable, which implied that plastic deformation of jointed specimens did not reach maximum value under smaller strain rate, and the growth rate of stress was greater than that of strain. Consequently, it was accepted practically that $E_{1}$ and $E_{2}$ were both independent of strain rate but were sensitive to joint angle.

Subsequently, the variable tendency of $E_{1}$ and $E_{2}$ versus joint angle was stated in detail under the strain rate of $85 \mathrm{~s}^{-1}$, as presented in Figure 8. The maximum and minimum values of $E_{1}$, respectively, occurred at intact specimen and specimen containing a joint angle of $45^{\circ}$, with a variable range from $24.82 \mathrm{GPa}$ to $69.07 \mathrm{GPa}$. The average value of $E_{1}$ for intact specimens was 1.74 times, 2.78 times, and 1.09 times as much as that of specimens containing a joint angle of $0^{\circ}, 45^{\circ}$, and $90^{\circ}$, separately. Moreover, V-shaped variable trend of $E_{1}$ was apparently demonstrated for jointed specimens. It was indicated that $E_{1}$ decreased linearly when joint angle increased from $0^{\circ}$ to $45^{\circ}$ and then increased to maximum value dramatically with incremental joint angle from $45^{\circ}$ to $90^{\circ}$. Similarly, the variable range of $E_{2}$ was from $3.84 \mathrm{GPa}$ to $31.77 \mathrm{GPa}$. The average maximum value of $E_{2}$ was occupied by intact specimen, which was 5.76 times, 8.27 times, and 1.17 times as much as that of specimens possessing a joint angle of $0^{\circ}, 45^{\circ}$, and $90^{\circ}$, respectively. When joint angle increased from $0^{\circ}$ to $45^{\circ}$, the values of $E_{2}$ for jointed specimens were all far less than those of intact specimens. And the value of $E_{2}$ performed a slight reduction when $\alpha \leq 45^{\circ}$ and increased remarkably from $3.84 \mathrm{GPa}$ to $27.19 \mathrm{GPa}$ when $\alpha \geq 45^{\circ}$. It meant that weakly filled joint

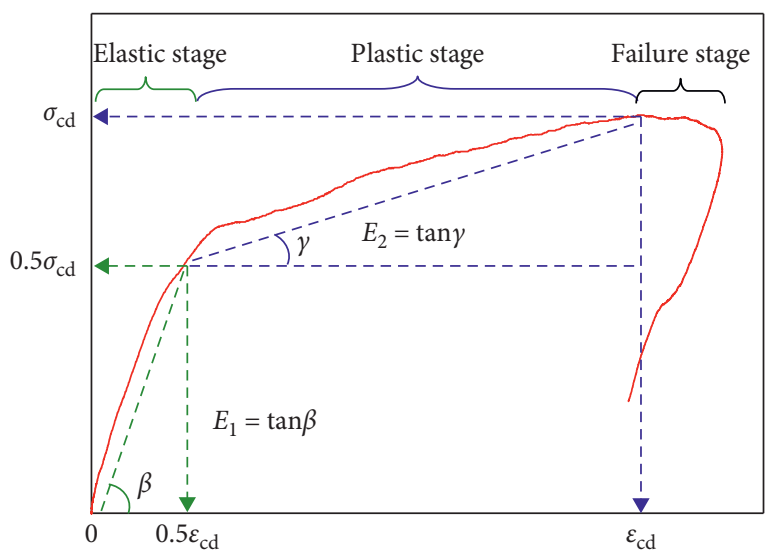

FIgURe 7: Defining method of elastic deformation modulus and plastic deformation modulus of jointed specimens.

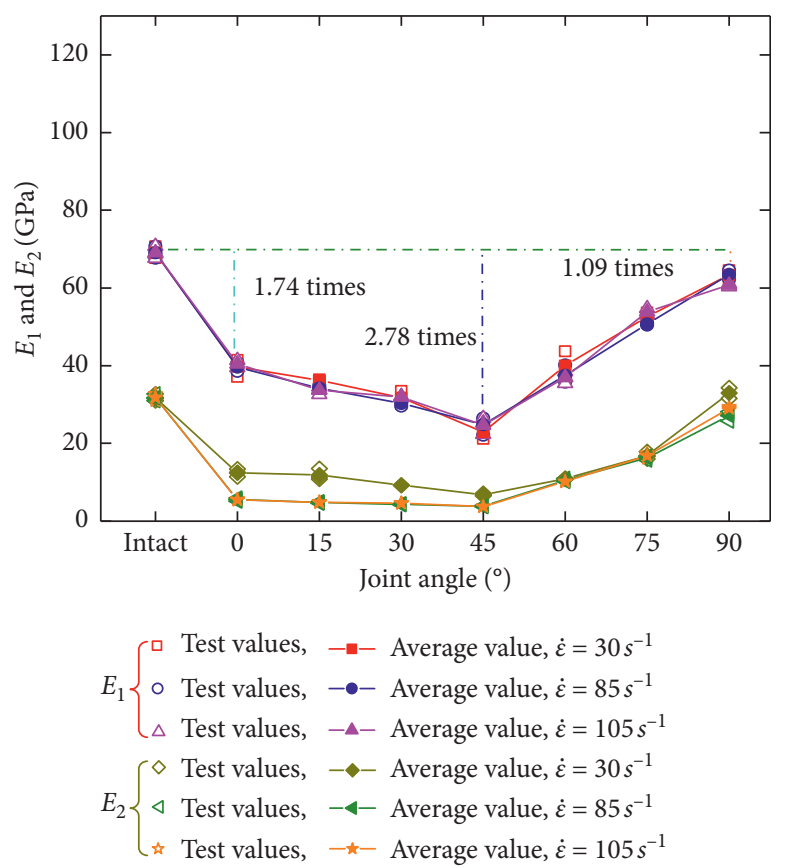

FIgURE 8: The variable tendency of $E_{1}$ and $E_{2}$ versus joint angle under three different strain rates.

could conspicuously decline the value of $E_{2}$, whereas $E_{2}$ was marginally influenced by joint angle when $\alpha \leq 45^{\circ}$. Consequently, $E_{1}$ and $E_{2}$ of jointed specimens were lower than those of intact specimens and presented different sensitivities to joint angle. The value of $E_{1}$ was dependent on joint angle, while the value of $E_{2}$ was significantly affected by joint angle only when $\alpha>45^{\circ}$ and was insensitive to joint angle when $\alpha \leq 45^{\circ}$.

\section{Energy Evolution Characteristic}

Energy dissipation was the internal mechanism for dynamic behavior of rock mass. Weakly filled joint had significant effects on stress wave propagation and energy dissipation behavior [36]. Analyses of energy transmission and transformation path were instrumental in ensuring stability and 
safety of underground engineering in design, construction, and service stage, especially for underground cavities surrounded by jointed rock masses. Conventionally, energy reflection coefficient $R_{W}$ and energy transmission coefficient $T_{W}$ were defined as the ratio of reflected energy $W_{R}$ and transmitted energy $W_{T}$ to incident energy $W_{I}$, respectively. And absorbed energy density $W_{D}$ was described as the ratio of absorbed energy $W$ to the volume of jointed specimens. Additionally, absorption energy release phenomenon of jointed specimens was observed under three-dimensional stress state in present study. Hence, released absorbed energy $\Delta W$ and absorbed energy release rate $W_{R R}$ were introduced to elaborate the storage and release behavior of absorbed energy, which were defined as the difference between maximum value and final value of absorbed energy and the ratio of absorbed energy release amount $\Delta W$ to absorbed energy $W$, respectively. In addition, only the energy evolution time curves were analyzed in detail under the strain rate of $30 \mathrm{~s}^{-1}$ and $105 \mathrm{~s}^{-1}$, because similar energy evolution characteristics were observed under the strain rate of $85 \mathrm{~s}^{-1}$ and $105 \mathrm{~s}^{-1}$.

4.1. Typical Energy-Time Curves. Energy-time curves possessing a joint angle of $15^{\circ}, 45^{\circ}$, and $75^{\circ}$ were selected as the typical representatives under the strain rate of $30 \mathrm{~s}^{-1}$ and $105 \mathrm{~s}^{-1}$, as plotted in Figure 9. It could be seen that the shapes of energy evolution-time curves for incident energy were consistent with each other. However, beyond incident energy, there were distinct differences in evolutionary characteristics of energy-time curves for reflected energy, transmitted energy, and absorbed energy. Absorbed energy release phenomenon was more notable under lower strain rate than that under higher strain rate. For specimen with a joint angle of $15^{\circ}$, absorbed energy reached the maximum value and then decreased, whereas the value of incident energy and reflected energy tended to be a constant. It was inferred that the released absorbed energy was mainly converted into transmitted energy from energy evolution-time curves. Moreover, the release phenomenon of absorbed energy was only observed under the strain rate of $30 \mathrm{~s}^{-1}$ for specimen containing a joint angle of $45^{\circ}$, which has implied that specimen containing a joint angle of $45^{\circ}$ still had certain bearing capacity after failure under threedimensional stress state. The decline section of absorption energy was corresponding to the rising section of reflection energy, as well as absorbed energy would keep a constant after reaching its peak value under higher strain rate, which could be considered that released energy was predominantly transformed into reflected energy. Furthermore, the released phenomena of absorbed energy were observed for specimen containing a joint angle of $75^{\circ}$ under three different strain rates coupled with three-dimensional stress state. And similar conversion paths of released energy were discerned, which was entitled section I with duration around $40 \mu$ s from $280 \mu$ s to $320 \mu$ s and section II with duration around $80 \mu \mathrm{s}$ from $320 \mu$ s to $400 \mu$ s. The released absorbed energy was mainly altered into transmitted energy in section I and reflected energy in section II, respectively.
Absorbed energy released phenomenon could be explained as follows. Preloading axial compressive stress and active confining stress propelled energy accumulation in jointed specimens. Under lower incident energy, the elastic and plastic energy gathered in jointed specimen was not enough to make specimens loss capacity ability, which brought about the release of elastic energy in absorbed energy. And the relative proportion of released absorbed energy in absorbed energy was on incline with higher incident energy. It was implied that the incremental incident energy accelerated the deterioration and damage of jointed rock masses and leaded to the reduction of residual elastic energy.

In terms of specimen with a joint angle of $15^{\circ}$, the increased rate of transmitted energy under the strain rate of $30 \mathrm{~s}^{-1}$ was slower than that under the strain rate of $105 \mathrm{~s}^{-1}$. The growth rate of reflected energy was the slowest under the strain rate of $30 \mathrm{~s}^{-1}$, which was alien to the evolutionary tendency of reflected energy under the strain rate of $105 \mathrm{~s}^{-1}$. And the increase rate of absorbed energy was always the fastest prior to reaching the maximum value. Moreover, for specimen with a joint angle of $45^{\circ}$, incident energy remained constant after reaching the maximum value at around $280 \mu \mathrm{s}$. The increase rate of reflected energy was always faster than that of transmitted energy and absorbed energy, while transmitted energy with a slowest growth rate has accounted for a much small part in incident energy and would be in plateaus period after reaching its maximum value, which indicated that specimen with a joint angle of $45^{\circ}$ was easy to be damaged under dynamic loading. Furthermore, for specimen possessing a joint angle of $75^{\circ}$, the increased rate of transmitted energy was the fastest compared with reflected energy and absorbed energy. Notably, reflected energy was even larger than absorbed energy in later stage of energy-time curve under three-dimensional stress state, which demonstrated that the available energy for rock breaking was less than the energy returned to incident bar.

4.2. Absorbed Energy Release Rate and Absorbed Energy Density. The relationship between absorbed energy release rate $W_{R R}$ and joint angle was presented in Figure 10. Similar variable tendency of absorbed energy release rate was observed, which slightly decreased to minimum value first and then dramatically increased to maximum value. There was a critical joint angle to minimize or maximize absorbed energy release rate, which was approximate to the joint angle of $45^{\circ}$ and $90^{\circ}$, respectively. The absorbed energy release rate under the strain rate of $30 \mathrm{~s}^{-1}$ was almost always larger than that under the strain rate of $85 \mathrm{~s}^{-1}$ or $105 \mathrm{~s}^{-1}$, except for that of specimen with a joint angle of $90^{\circ}$. While the difference of absorbed energy release rate under the strain rate of $85 \mathrm{~s}^{-1}$ and $105 \mathrm{~s}^{-1}$ was insignificant for jointed specimens. The mechanism behind these phenomena could be summarized as follows. The lower incident energy resulted in slight damage of jointed specimens under three-dimensional stress rate, which was instrumental in the storage and release of elastic energy, while jointed specimens were seriously damaged by higher incident energy, especially for weakly 


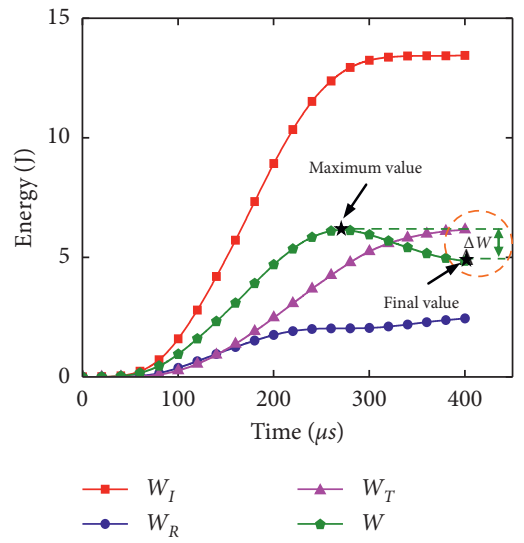

(a)

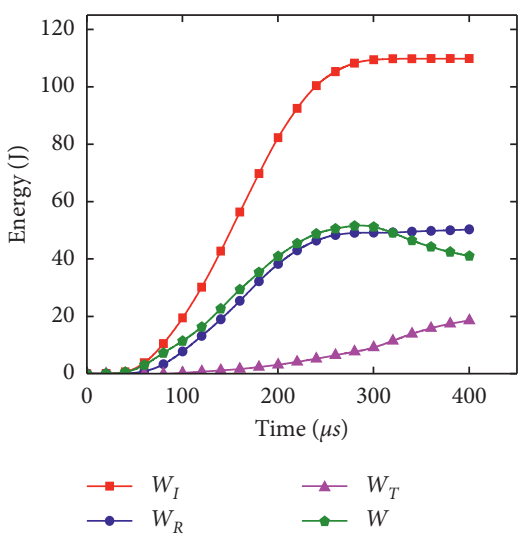

(d)

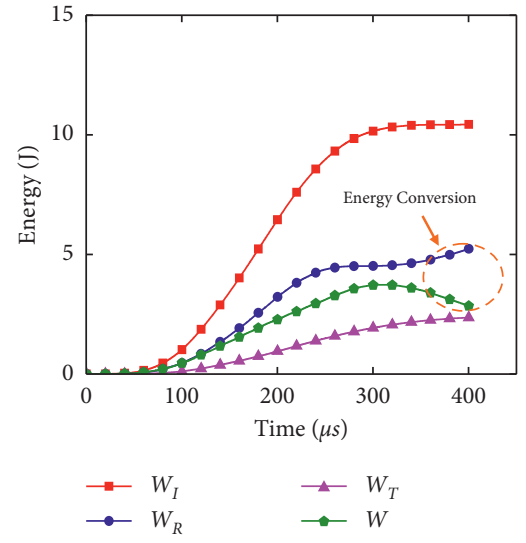

(b)

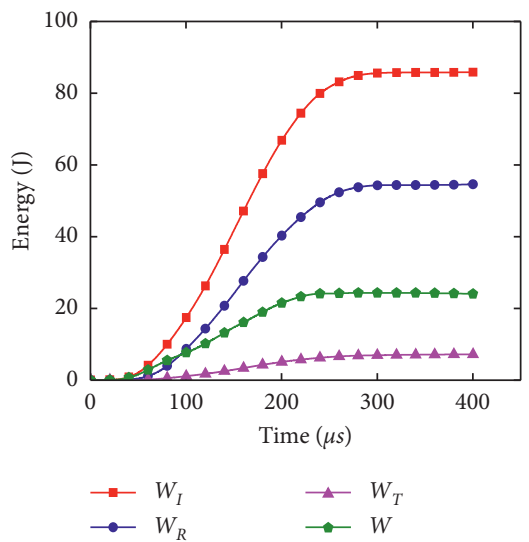

(e)

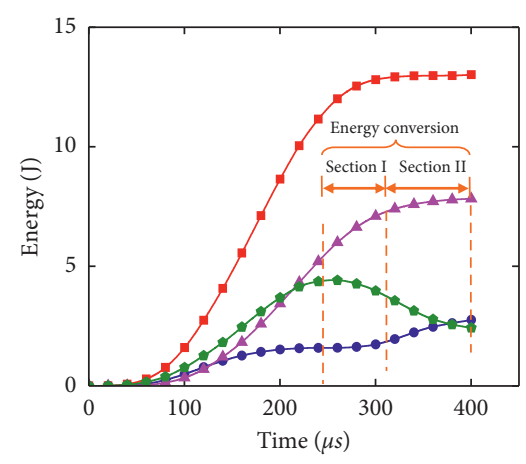

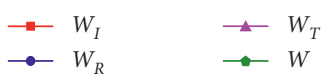

(c)

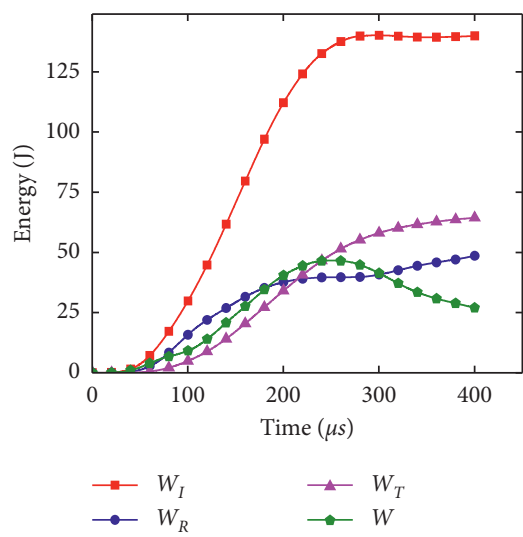

(f)

FIGURE 9: Typical energy-time curves. (a) and (d) for specimen with a joint angle of $15^{\circ}$ under strain rate of $30 \mathrm{~s}^{-1}$ and $105 \mathrm{~s}^{-1}$, respectively; (b) and (e) for specimen with a joint angle of $45^{\circ}$ under strain rate of $30 \mathrm{~s}^{-1}$ and $105 \mathrm{~s}^{-1}$, respectively; and (c) and (f) for specimen with a joint angle of $75^{\circ}$ under strain rate of $30 \mathrm{~s}^{-1}$ and $105 \mathrm{~s}^{-1}$, respectively.

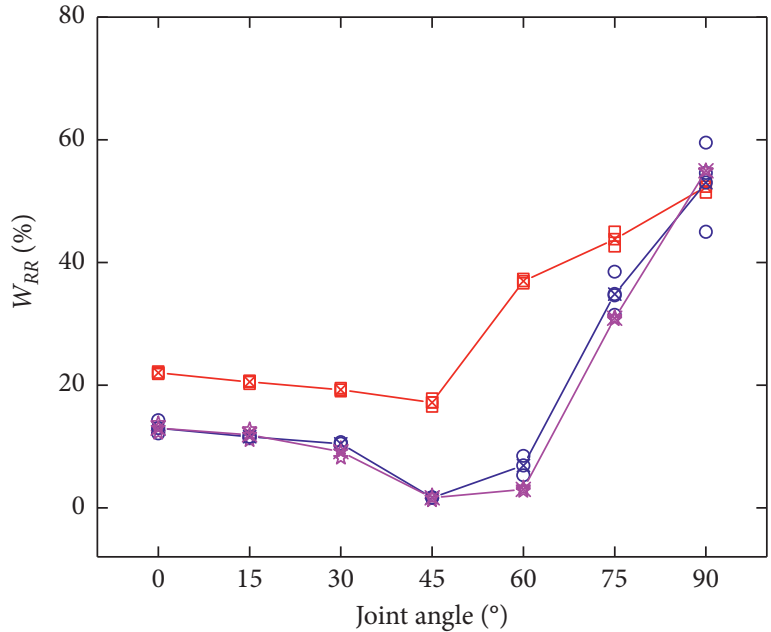

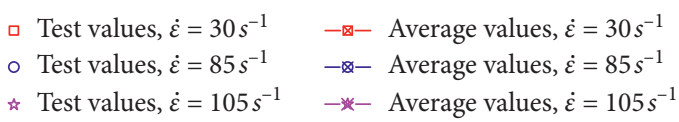

FIgURE 10: The variable tendency of $W_{R R}$ with joint angle under three different strain rates. filled joint, without excess elastic energy being released. From Figure 11, there was an obvious linear relationship between absorption energy density and joint angle [37]. And the absorption energy density was decreased linearly with the increase of joint angle under the strain rate of $85 \mathrm{~s}^{-1}$ or $105 \mathrm{~s}^{-1}$, whereas a minor variation was exposed with mounting joint angle under the strain rate of $30 \mathrm{~s}^{-1}$. These phenomena could be explained as follows. The degree of compression failure of joint decreased with the increase of joint angle, and crack propagation in jointed specimens was confined by three-dimensional stress state, which leaded to a gradual decrease in absorbed energy utilized for jointed rock breaking. However, lower incident energy was not enough to destroy jointed specimens under three-dimensional stress state, the degree of crack initiation and propagation was similar for specimens containing weakly filled joint at various angles, with a modest variety in absorbed energy density.

4.3. Energy Transmission Coefficient and Energy Reflection Coefficient. Figures 12 and 13 characterized the changing trajectory of energy reflection coefficient $R_{W}$ and energy transmission coefficient $T_{W}$ against joint angle under three 


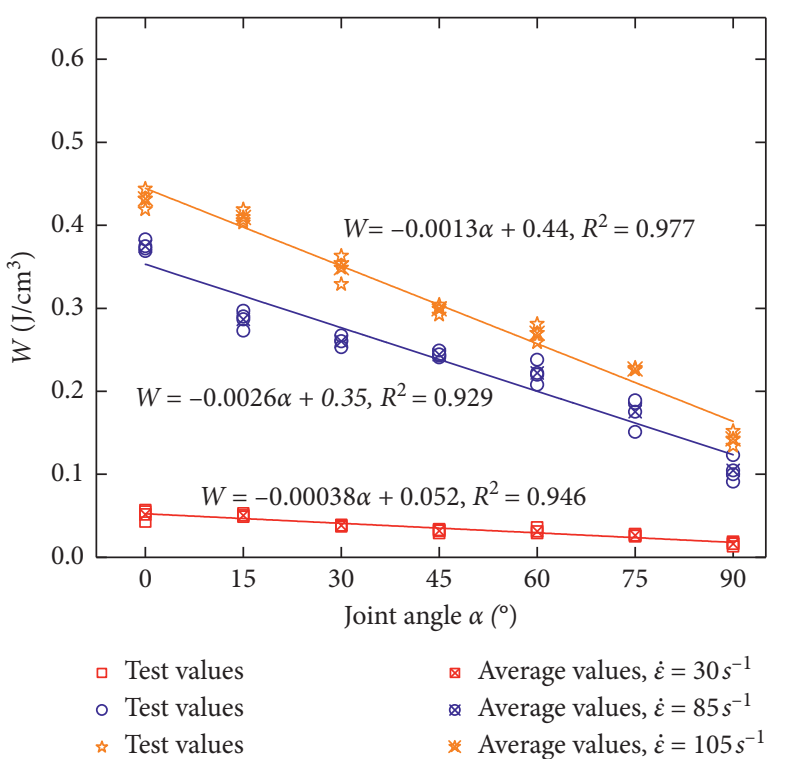

FIgURE 11: Variation in $W$ with joint angle under three different strain rates.

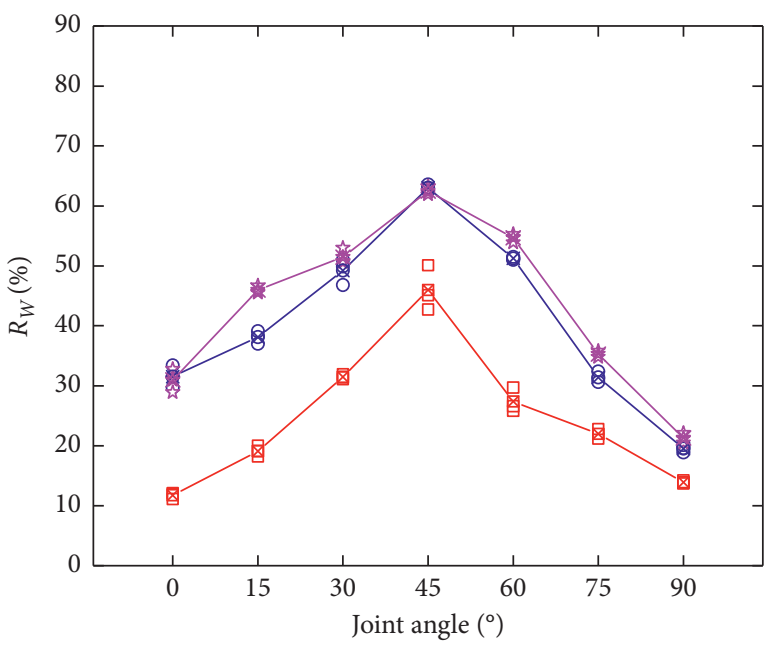

$$
\begin{array}{ll}
\square \text { Test values } & -\varangle-\text { Average values, } \dot{\varepsilon}=30 \mathrm{~s}^{-1} \\
- \text { Test values } & -- \text { Average values, } \dot{\varepsilon}=85 \mathrm{~s}^{-1} \\
\text { ↔ Test values } & -*-\text { Average values, } \dot{\varepsilon}=105 \mathrm{~s}^{-1}
\end{array}
$$

Figure 12: Variation in $R_{W}$ with joint angle under three different strain rates.

different strain rates, respectively. Notably synchronous ascending tendency of energy reflected coefficient was discovered when joint angle increased from $0^{\circ}$ to $45^{\circ}$, which was opposite to that when joint angle increased from $45^{\circ}$ to $90^{\circ}$. The value of energy reflection coefficient under the strain rate of $105 \mathrm{~s}^{-1}$ was marginally larger than that under the strain rate of $85 \mathrm{~s}^{-1}$, but conspicuously larger than that under the strain rate of $30 \mathrm{~s}^{-1}$. The variable trend of energy transmission coefficient was completely contrary to that of energy reflection coefficient through comparative analysis of Figures 12 and 13 [38]. The reasons could be epitomized as follows. Jointed specimens were consolidated, compacted,

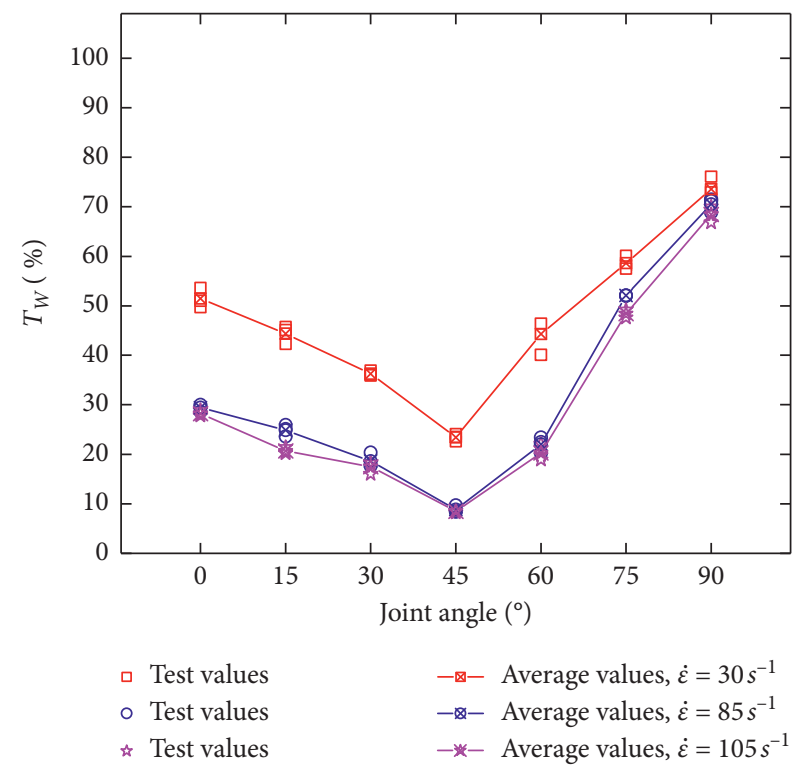

FIgURE 13: Variation in $T_{W}$ with joint angle under three different strain rates.

and still in elastic state under three-dimensional stress state coupled with the strain rate of $30 \mathrm{~s}^{-1}$, which would contribute to the propagation of transmission wave. Conversely, under the conditions of higher strain rate, crack initiation and propagation in jointed specimens would inevitably count against the propagation of transmission wave. However, the higher the strain rate was, the more abundant the crack developed, leading to the increase of energy reflection surface, which in turn resulted in an increase in the energy reflection coefficient.

\section{Conclusions}

Dynamic impact tests were conducted by employing SHPB apparatus to investigate the effects of weakly filled joint at seven kinds of angles on dynamic behavior and energy evolution characteristic of sandstone under three-dimensional stress state. Summative conclusions were reached as follows.

(1) Rebound strain phenomenon was observed from stress-strain curves of jointed specimens. The stress generally showed the growth rate of "fast-slow-slowfast" four sections characteristics for specimens containing a joint angle of $0^{\circ}, 15^{\circ}, 30^{\circ}$, and $45^{\circ}$, with obvious plastic failure feature, whereas for specimens possessing a joint angle of $60^{\circ}, 75^{\circ}$, and $90^{\circ}$, the stress displayed the growth rate of "fast-fast" two sections characteristics, showing typical brittle failure behavior.

(2) Dynamic compressive strength, elastic deformation modulus, and plastic deformation modulus were all changed in $\mathrm{V}$-shape with the incremental joint angle from $0^{\circ}$ to $90^{\circ}$, whose maximum value and minimum value occurred at $45^{\circ}$ and $90^{\circ}$, respectively. However, dynamic peak strain was gradually descending with 
the mounting joint angle. Both elastic deformation modulus and plastic deformation modulus were independent of strain rate, which was opposite to dynamic compressive strength and dynamic peak strain. The value of elastic deformation modulus was dependent on joint angle. While the value of plastic deformation modulus was significantly affected by joint angle only when $\alpha>45^{\circ}$ and was insensitive to joint angle when $\alpha \leq 45^{\circ}$.

(3) The value of energy reflection coefficient under the strain rate of $105 \mathrm{~s}^{-1}$ was marginally larger than that under the strain rate of $85 \mathrm{~s}^{-1}$ and conspicuously larger than that under the strain rate of $30 \mathrm{~s}^{-1}$, with inverted $\mathrm{V}$-shaped change, which was completely contrary to the variable trend of energy transmission coefficient and absorbed energy release rate. And the released absorption energy was mainly converted into transmitted energy and reflected energy from energy evolution-time curves. Absorbed energy density was linearly decreased with incremental joint angle and was increased with the increase of strain rate.

\section{Data Availability}

The datasets generated and analyzed during the current study are available from the corresponding author on reasonable request.

\section{Conflicts of Interest}

The authors declare that there are no conflicts of interest regarding the publication of this paper.

\section{Acknowledgments}

This research received financial support from the National Natural Science Foundation of China (no. 51774011). Thanks are due to the State Key Laboratory of Mining Response and Disaster Prevention and Control in Deep Coal Mine and Engineering Research Center of Underground Mine Construction, Ministry of Education of China, Anhui University of Science and Technology, for providing the experiment conditions.

\section{References}

[1] E. Hoek, "Practical rock engineering," Environmental and Engineering Geoscience, vol. 14, no. 1, pp. 55-57, 2008.

[2] C. H. Park and A. Bobet, "Crack coalescence in specimens with open and closed flaws: a comparison," International Journal of Rock Mechanics and Mining Sciences, vol. 46, no. 5, pp. 819-829, 2009.

[3] H. Saroglou and G. Tsiambaos, "A modified Hoek-Brown failure criterion for anisotropic intact rock," International Journal of Rock Mechanics and Mining Sciences, vol. 45, no. 2, pp. 223-234, 2008.

[4] S. P. Morgan, C. A. Johnson, and H. H. Einstein, "Cracking processes in Barre granite: fracture process zones and crack coalescence," International Journal of Fracture, vol. 180, no. 2, pp. 177-204, 2013.
[5] F.-Q. Gong and G.-F. Zhao, "Dynamic indirect tensile strength of sandstone under different loading rates," Rock Mechanics and Rock Engineering, vol. 47, no. 6, pp. 2271-2278, 2014.

[6] F.-Q. Gong, X.-F. Si, X.-B. Li, and S.-Y. Wang, "Dynamic triaxial compression tests on sandstone at high strain rates and low confining pressures with split Hopkinson pressure bar," International Journal of Rock Mechanics and Mining Sciences, vol. 113, pp. 211-219, 2019.

[7] X. Li, F. Feng, D. Li, K. Du, P. G. Ranjith, and J. Rostami, "Failure characteristics of granite influenced by sample height-to-width ratios and intermediate principal stress under true-triaxial unloading conditions," Rock Mechanics and Rock Engineering, vol. 51, no. 5, pp. 1321-1345, 2018.

[8] J. Zhao and H. B. Li, "Experimental determination of dynamic tensile properties of a granite," International Journal of Rock Mechanics and Mining Sciences, vol. 37, no. 5, pp. 861-866, 2000.

[9] R. Shan, Y. Jiang, and B. Li, “Obtaining dynamic complete stress-strain curves for rock using the split Hopkinson pressure bar technique," International Journal of Rock Mechanics and Mining Sciences, vol. 37, no. 6, pp. 983-992, 2000.

[10] X.-T. Feng and W. Ding, "Experimental study of limestone micro-fracturing under a coupled stress, fluid flow and changing chemical environment," International Journal of Rock Mechanics and Mining Sciences, vol. 44, no. 3, pp. 437-448, 2007.

[11] F.-q. Gong, Y. Luo, X.-b. Li, X.-f. Si, and M. Tao, "Experimental simulation investigation on rockburst induced by spalling failure in deep circular tunnels," Tunnelling and Underground Space Technology, vol. 81, pp. 413-427, 2018.

[12] J. Wu, M. Feng, G. Han, B. Yao, and X. Ni, "Loading rate and confining pressure effect on dilatancy, acoustic emission, and failure characteristics of fissured rock with two pre-existing flaws," Comptes Rendus Mécanique, vol. 347, no. 1, pp. 62-89, 2019.

[13] Y. Bai, R. L. Shan, Y. Ju et al., "Experimental study on the strength, deformation and crack evolution behaviour of red sandstone samples containing two ice-filled fissures under triaxial compression," Cold Regions Science and Technology, vol. 147, pp. 1-21, 2020.

[14] S. Y. Wang, S. W. Sloan, D. C. Sheng, S. Q. Yang, and C. A. Tang, "Numerical study of failure behaviour of precracked rock specimens under conventional triaxial compression," International Journal of Solids and Structures, vol. 51, no. 5, pp. 1132-1148, 2014.

[15] Y. Z. Yang and Z. N. Zhang, "Dynamic fracturing process of fissured rock under abrupt unloading condition: a numerical study," Engineering Fracture Mechanics, vol. 231, pp. 1-16, 2020.

[16] D. Li, Q. Zhu, Z. Zhou, X. Li, and P. G. Ranjith, "Fracture analysis of marble specimens with a hole under uniaxial compression by digital image correlation," Engineering Fracture Mechanics, vol. 183, no. 9, pp. 109-124, 2017.

[17] Y. Liu and F. Dai, "A damage constitutive model for intermittent jointed rocks under cyclic uniaxial compression," International Journal of Rock Mechanics and Mining Sciences, vol. 103, pp. 289-301, 2018.

[18] S.-Q. Yang, P.-F. Yin, Y.-C. Zhang et al., "Failure behavior and crack evolution mechanism of a non-persistent jointed rock mass containing a circular hole," International Journal of Rock Mechanics and Mining Sciences, vol. 114, pp. 101-121, 2019. 
[19] X. Si and F. Gong, "Strength-weakening effect and sheartension failure mode transformation mechanism of rock burst for fine-grained granite under triaxial unloading compression," International Journal of Rock Mechanics and Mining Sciences, vol. 131, p. 104347, 2020.

[20] X. Liu, F. Dai, R. Zhang, and J. Liu, "Static and dynamic uniaxial compression tests on coal rock considering the bedding directivity," Environmental Earth Sciences, vol. 73, no. 10, pp. 5933-5949, 2015.

[21] P. Yuan and $\mathrm{Y} . \mathrm{Xu}$, "Influence of layered joints on zonal disintegration in deep rock masses under coupled high in-situ axial stress and blasting load," The Journal of the Southern African Institute of Mining and Metallurgy, vol. 119, pp. 1019-1026, 2019.

[22] Z. Y. Han, D. Y. Li, Q. Q. Zhu, M. Liu, and Z. Sun, "Dynamic fracture evolution and mechanical behavior of sandstone containing noncoplanar elliptical flaws under impact loading," Advances in Civil Engineering, vol. 2018, Article ID 5649357, 16 pages, 2018.

[23] J. C. Li, L. F. Rong, H. B. Li, and S. N. Hong, "An SHPB test study on stress wave energy attenuation in jointed rock masses," Rock Mechanics and Rock Engineering, vol. 52, pp. 403-420, 2019.

[24] W. Wang, H. Hao, X. Li, Z. Yan, and F. Gong, "Effects of a single open joint on energy transmission coefficients of stress waves with different waveforms," Rock Mechanics and Rock Engineering, vol. 48, no. 5, pp. 2157-2166, 2015.

[25] D. Y. Li, C. W. Hu, and Q. Q. Zhu, "Experimental study on mechanical properties and failure laws of granite with an artificial flaw under coupled static and dynamic loads," Chinese Journal of Rock Mechanics and Engineering, vol. 39, no. 6, pp. 1081-1093, 2020.

[26] R. Chen, W. Yao, F. Lu, and K. Xia, "Evaluation of the stress equilibrium condition in axially constrained triaxial SHPB tests," Experimental Mechanics, vol. 58, no. 3, pp. 527-531, 2018.

[27] Y. Zou, J. Li, L. Laloui, and J. Zhao, “Analytical time-domain solution of plane wave propagation across a viscoelastic rock joint," Rock Mechanics and Rock Engineering, vol. 50, no. 10, pp. 2731-2747, 2017.

[28] J. G. Cai and J. Zhao, "Effects of multiple parallel fractures on apparent attenuation of stress waves in rock masses," International Journal of Rock Mechanics and Mining Sciences, vol. 37, no. 4, pp. 661-682, 2000.

[29] J. B. Zhu, A. Perino, G. F. Zhao et al., "Seismic response of a single and a set of filled joints of viscoelastic deformational behaviour," Geophysical Journal International, vol. 186, no. 3, pp. 1315-1330, 2011.

[30] X. F. Li, H. B. Li, J. C. Li, and Z. W. Li, "Research on transient wave propagation across nonlinear joints filled with granular materials," Rock Mechanics and Rock Engineering, vol. 51, no. 8, pp. 2373-2393, 2018.

[31] Y. X. Zhou, K. Xia, X. B. Li et al., "Suggested methods for determining the dynamic strength parameters and mode-I fracture toughness of rock materials," International Journal of Rock Mechanics and Mining Sciences, vol. 49, no. 1, pp. 105-112, 2012.

[32] D. Ma, Q. Ma, and P. Yuan, "SHPB tests and dynamic constitutive model of artificial frozen sandy clay under confining pressure and temperature state," Cold Regions Science and Technology, vol. 136, pp. 37-43, 2017.

[33] G. Z. Sun, Structure Mechanics of Rock Mass, Science Press, Beijing, China, 1988.
[34] S. H. Li, W. C. Zhu, L. L. Niu, M. Yu, and C. F. Chen, "Dynamic characteristics of green sandstone subjected to repetitive impact loading: phenomena and mechanisms," Rock Mechanics and Rock Engineering, vol. 51, no. 1, pp. 1921-1936, 2018.

[35] Q. Y. Ma, Q. Q. Su, D. D. Ma, and P. Yuan, "Characteristics of dynamic failure of sandstone containing weakly filled joint with various angles in deep roadway under split Hopkinson pressure bar tests," Chinese Journal of Rock Mechanics and Engineering, vol. 39, no. 6, pp. 1104-1116, 2020.

[36] S. Aziznejad, K. Esmaieli, J. Hadjigeorgiou, and D. Labrie, "Responses of jointed rock masses subjected to impact loading," Journal of Rock Mechanics and Geotechnical Engineering, vol. 10, no. 4, pp. 624-634, 2018.

[37] X. B. Li, T. S. Lok, and J. Zhao, "Dynamic characteristics of granite subjected to intermediate loading rate," Rock Mechanics and Rock Engineering, vol. 38, no. 1, pp. 21-39, 2005.

[38] D. Li, Z. Han, Q. Zhu, Y. Zhang, and P. G. Ranjith, "Stress wave propagation and dynamic behavior of red sandstone with single bonded planar joint at various angles," International Journal of Rock Mechanics and Mining Sciences, vol. 117, pp. 162-170, 2019. 